\title{
CERVANTES, BORGES E EU: QUEM É O AUTOR DA CONSTITUIÇÃO?
}

\author{
MARCElo CAMpos GALUPPo ${ }^{2}$
}

\begin{abstract}
RESUMO: A literatura pode ensinar-nos muito sobre o direito, quando, por exemplo, utilizamos o conceito de autor para compreender o desenvolvimento de textos normativos. Esse conceito cria uma tarefa para o campo de estudo do Direito e Literatura: determinar quem é o autor da Constituição, e como é possível ao leitor do texto constitucional reconhecer-se no lugar de seu autor. Esse problema, que opõe os autores do originalismo e da living constitution, pode ser melhor compreendido se concebermos o texto constitucional como um espelho (mise-en-abyme): ainda que elaborado pelo poder constituinte originário, o que ele reflete é quem de fato se olha em tal espelho. A partir dessa perspectiva, proponho que a Constituição seja compreendida a partir da tensão entre seu sentido e sua referência (ou denotação).
\end{abstract}

PalaVras-Chave: direito e literatura; constituição; constituinte; mise-en-abyme; interpretação constitucional.

\section{QUEM ESCREVEU O QUIXOTE? O AUTOR DENTRO DO TEXTO}

Há obras que tanto se sedimentaram no imaginário coletivo que não percebemos que elas não são exatamente o que pensamos que elas sejam, como no caso do célebre monólogo de Hamlet, em que o protagonista,

1 Este trabalho foi originalmente apresentado durante o $\mathrm{V}$ Colóquio Internacional de Direito e Literatura - CIDIL - realizado em Uberaba entre os dias 26 e 28 de outubro de 2016, e com o financiamento do CNPq através da Bolsa Pq concedida ao autor, além do apoio do PROEX-CAPES da PUC Minas.

2 Doutor em Filosofia do Direito pela UFMG. Professor da Faculdade Mineira de Direito da Pontifícia Universidade Católica de Minas Gerais (PUC Minas). Professor da Faculdade de Direito da Universidade Federal de Minas Gerais (UFMG) Belo Horizonte (MG), Brasil. ORCID: $\quad$ https://orcid.org/0000-0003-2329-6695. CV Lattes: http://lattes.cnpq.br/3883590920517833. Email: marcelogaluppo@uol.com.br. 
tomado por questões metafísicas e com uma caveira nas mãos, discorre sobre a hesitação diante de nossa condição efêmera, transitória e miserável. No texto de Shakespeare, nada disso ocorre. Ou melhor, ocorrem eventos distintos: no III ato, Hamlet realiza o célebre monólogo To be, or not to be, e somente na cena do coveiro, no $\mathrm{V}$ ato, ele segura em suas mãos a caveira de Yorick (Shakespeare, 2004).

Livros não lidos, livros mal lidos e livros esquecidos povoam nosso imaginário, e mesmo o homem culto terá sempre em seu currículo muitos livros não lidos. Isso talvez não seja relevante, pois, segundo a tese de Pierre Bayard, em Como falar dos livros que não lemos? (2007), mais importante do que ler os livros é possuir uma visão de conjunto que permita compreender a inserção de determinada obra no cânon literário:

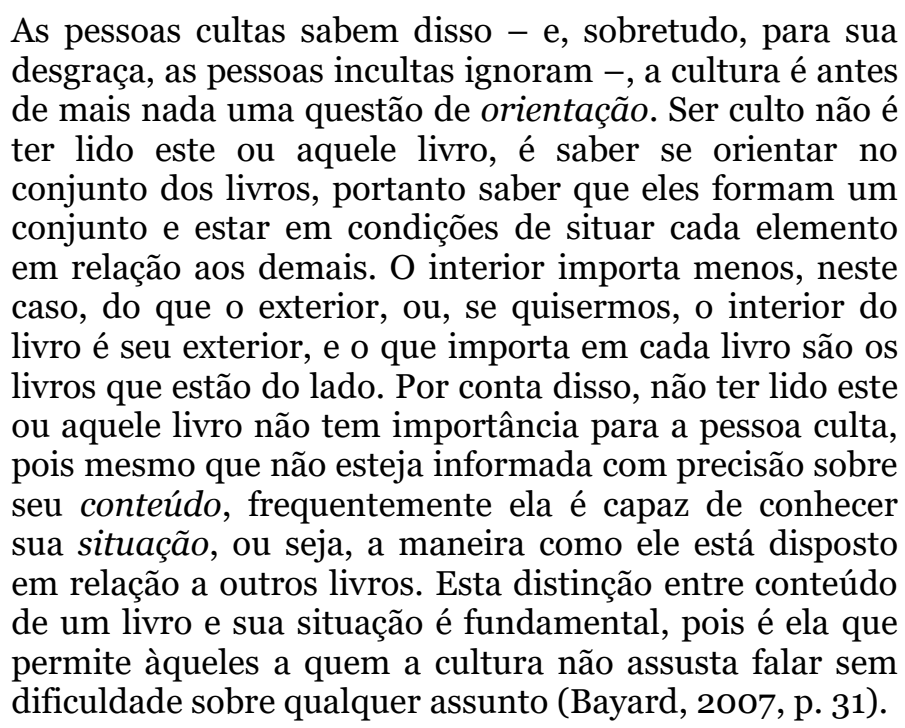

Hamlet é uma obra que conhecemos sem termos lido, e o mesmo ocorre com Dom Quixote da Mancha, livro que o crítico Harold Bloom levaria para uma ilha deserta, se pudesse trazer consigo também a edição folio de Shakespeare e a Bíblia na versão King James (Bloom, 2005), e que muito poucos leram, apesar de poucos terem a coragem ou a ingenuidade necessárias para reconhecê-lo.

Por não ter lido o Quixote, o leitor contemporâneo mal consegue perceber que o que considera ser a obra de um único autor, Miguel de Cervantes, é, no mínimo, obra de dois: Cervantes e Pierre Menard. Os estudos mais recentes indicam que dificilmente pode-se dar razão a Jorge Luís Borges, para quem o Quixote de Menard é apenas uma recriação linha por linha, palavra por palavra, ipsis literis, quase um plágio do Quixote de 
Cervantes. Recriação idêntica, mas com um significado distinto, pensa Borges. (1998, p. 496). No entanto, é preciso reconhecer que pelos menos três capítulos do Quixote de Cervantes não poderiam ter sido escritos pelo autor espanhol (pois pressuporiam o conhecimento de fatos muito posteriores à morte de Cervantes), e parece ser indiscutível a autoria de Pierre Menard desses trechos (notadamente no capítulo VIII). Uma crítica textual simples pode constatar isso. É evidente, por exemplo, a alteração diegética ${ }^{3}$ operada no início do capítulo IX de Dom Quixote da Mancha, em que, excepcionalmente, Dom Quixote consegue vencer um inimigo (o que também é um índice da existência de um novo autor, pois, no Quixote original, este é sempre ridiculamente derrotado, ainda que não consiga percebê-lo). A essa altura do Quixote, Menard percebe que o episódio do encontro de Dom Quixote com um biscainho havia sido deixado inconcluso por Cervantes e, adotando um estilo narrativo diverso, resolve inserir um novo capítulo para, como em um intermezzo, dar seguimento à trama de Cervantes. Isso fica evidente na passagem final do capítulo VIII e na passagem inicial do capítulo IX:

\begin{abstract}
Neste ponto e altura deixa pendente o autor desta história esta batalha, com a desculpa de que não encontrou nenhum outro escrito destas façanhas de D. Quixote além das que deixa referidas. É verdade, porém, que o segundo autor desta obra não quis crer que tão cuidadosa história estivesse entregue às leis do esquecimento, nem que houvessem sido tão pouco curiosos os engenhos da Mancha que não tivessem em seus arquivos ou em suas escrivaninhas alguns papéis que deste famoso cavaleiro tratassem; e assim, com esta imaginação, não se desesperou de achar o fim desta aprazível historia, o qual, sendo-lhe o céu favorável, ele achou do modo como se contará na segunda parte.
\end{abstract}

\title{
CAPÍTULO IX \\ Onde se leva a cabo e dá fím à estupenda batalha que o galhardo biscainho e o valente manchego travaram
}

Deixamos na primeira parte desta história o valoroso biscainho e o famoso D. Quixote com as espadas levantadas e desnudas, prestes a desferir dois furibundos fendentes, tais que, se em cheio acertassem, pelos menos se partiriam e fenderiam de cima a baixo e se abririam

3 Diegese é, de acordo com Genette, “o universo espaço-temporal designado pela narrativa; portanto, [...] diegético é o que pertence à estória" (1995, p. 273). Ou ainda, segundo Greimas e Courtés, diegese "designa o aspecto narrativo do discurso [e], nesse sentido, a noção se aproxima dos conceitos de história e de narrativa” ([198?]. p. 121). 
como uma romã; e neste ponto tão incerto parou e fitou truncada tão saborosa história, sem que nos desse notícia seu autor de onde se poderia encontrar o que dela faltava. Causou-me isso muito pesar, porque o gosto de haver lido tão pouco se mudava em desgosto de pensar no árduo caminho que se apresentava para encontrar o muito que a meu ver faltava de tão saboroso conto. Pareceu-me coisa impossível e fora de todo e qualquer bom costume que a tão bom cavaleiro lhe houvesse faltado algum sábio que tomara a seu cargo escrever suas nunca vistas façanhas, coisa que não faltou a nenhum dos cavaleiros andantes (Cervantes Saavedra, 2005, p. 102 e 105).

O texto (descuidadamente publicado em qualquer edição do Quixote sem qualquer observação à coautoria de Pierre Menard, apesar da referência explícita a um segundo autor) é claro e não demanda interpretação: quem "neste ponto parou" foi "seu autor", Cervantes, deixando a história truncada, razão pela qual o leitor do Quixote, Menard, o "segundo autor", cheio de pesar pela inconclusão da trama, entende-se no dever de continuar a história do cavaleiro da triste figura, a partir de uma fonte secundária e posterior da estória que obtivera e que ele mesmo narra como se lhe chegou:

Estando eu um dia no Alcaná de Toledo, chegou um rapaz a vender uns cartapácios e papéis velhos a um mercador de seda; e, como eu sou um aficionado de ler ainda que sejam os papéis rasgados das ruas, impelido por esta minha natural inclinação, tomei um cartapácio dos que o rapaz vendia e vi-o com caracteres que reconheci serem árabes. E, como conquanto os conhecesse não os sabia ler, fiquei olhando para ver se aparecia por ali algum mourisco aljamiado que os lesse, e não foi mui dificultoso achar semelhante intérprete, pois, ainda que o procurasse de outra melhor e mais antiga língua, o encontraria. Por fim, a sorte me deparou um, que, dizendo-lhe meu desejo e pondo-lhe o livro nas mãos, o abriu ao acaso e, lendo um pouco dele, começou a rir-se.

Perguntei-lhe eu de que se ria, e respondeu-me que de uma coisa que tinha aquele livro escrita na margem como anotação. Disse-lhe que ma dissesse, e ele, sem deixar de rir-se, disse:

- Está, como disse, aqui na margem escrito isso: "Esta Dulcineia do Toboso, tantas vezes nesta história referida, dizem que tinha melhor mão para salgar porcos que qualquer outra mulher de toda a Mancha”.

Quando eu ouvi dizer "Dulcineia do Toboso", fiquei atônito e pasmo, porque logo se me afigurou que aqueles cartapácios continham a história de D. Quixote (Cervantes Saavedra, 2005, p. 106). 
Menard, portanto, não se contenta em copiar Cervantes, como pensava Borges, mas o emenda nas passagens em que crê poder melhorar a trama. Progressivamente, essa emenda foi sendo incorporada ao texto do Quixote e esquecemo-nos paulatinamente de que se tratava de uma adição de Menard.

Até aqui foi dita uma meia verdade, com aparência mimética de verdade absoluta. Pierre Menard é, na verdade, uma invenção de Borges, que, no livro Ficciones, escreve um conto chamado Pierre Menard, autor de Quijote (1998). Subvertendo os gêneros literários, sob a aparência de fazer crítica, Borges produz ficção4. E por isso, sabemos agora, o verdadeiro autor do Quixote, ao lado do protagonismo de Cervantes, é na verdade o próprio Borges, que assume o pseudônimo de Menard. Menard não passa do personagem narrador, homodiegético ${ }^{5}$, do texto de Borges.

Mas a complexidade do conto leva-nos a reconhecer que Menard é um heterônimo de Borges, e por isso, para sermos fiéis à verdade, o Quixote não é obra de dois autores, Cervantes e Borges, mas de três: Cervantes, Borges e seu heterônimo, Menard. Borges, sob a aparência de fazer crítica literária, na verdade altera o próprio corpus do texto de Cervantes, tornando-se seu coautor, mas o faz sob a forma de um alter ego, e por isso precisamos reconhecer que não é propriamente Borges, mas o Menard de Borges, quem é o (co)autor do Quixote.

Pode-se subverter a verdade dizendo-se apenas verdades, e foi isso que acabou de se fazer. Esse Borges aqui descrito nunca existiu. Existiu, sim, um Jorge Luís Borges, autor do conto Pierre Menard, autor de Quijote. Mas esse Jorge Luís Borges não é exatamente acima descrito: alguém que assumira um pseudônimo e premeditadamente produziu um embuste, uma contrafação, tornando-se coautor da versão ora circulante de Dom Quixote. Não há nenhuma adição ao texto original de Cervantes, e o

4 São de fato gêneros diversos, a ficção e a crítica? Veremos a seguir que não, uma vez que a fortuna crítica do texto incorpora-se no imaginário da recepção desse texto.

5 O narrador homodiegético é, na nomenclatura de Genette, alguém que está presente na trama que por ele é narrada, enquanto o narrador heterodiegético é alguém que não participa da trama que ele conta. 
texto citado acima é da lavra do autor espanhol ${ }^{6}$. Na verdade, Borges esperava que o leitor passasse pelo teste da subversão do gênero literário7 e reconhecesse que tudo não passava de uma das muitas ficções (nome do próprio livro de Borges).

Mas esse Borges aqui descrito escreveu o conto com uma intenção diversa da intenção que o Borges real atribuía à sua obra. O Borges descrito acima teria escrito o conto com a intenção de enganar o leitor ${ }^{8}$. Em outras palavras, o Borges descrito acima é uma invenção do autor do presente artigo, uma nova meio-verdade, uma nova aparência mimética ${ }^{9}$ de verdade absoluta. Quixote, portanto, não é obra de três autores, Cervantes, Menard e Borges, mas de quatro: Cervantes, Menard, Borges e o autor deste artigo.

Um novo autor (o autor do presente artigo) de um texto sobre um outro autor (Borges) de um outro texto sobre um autor (Menard) que emenda um texto de um outro autor (Cervantes): Vemos aqui aquilo que ficou conhecido como o efeito Droste, uma marca de chocolate holandesa em cuja propaganda uma moça segura um pote de chocolate no qual está impressa uma moça segurando um pote de chocolate, no qual se vê uma moça segurando um pote de chocolate, imagem que se replica infinitamente, mis-en-abyme, um tipo de narrativa que lança mão da recorrência, na qual o elemento mimetizado está representado em vários níveis, como a peça de teatro encenada dentro da peça de teatro, no terceiro ato de Hamlet, ou como o pintor Velasquez, que pinta-se a si mesmo (ele, que pinta o próprio quadro) em As Meninas: um espelho que reflete outro

6 O jogo que Cervantes realiza de esconder-se no texto e de nele se revelar, de assumir-se como autor do texto, portanto, é o que faz dele, provavelmente, um dos primeiros autores modernos, como mostra Douglas Price (2017).

7 O tema da subversão do gênero é de fundamental importância para o Direito, sobretudo no Brasil de hoje. Henriete Karam, por exemplo, deixa claro que, enquanto para o gênero da crítica literária o tema do fundamento (racional) é central, para o gênero do romance, que substitui a verdade pela verossimilhança, o tema central é o tema da originalidade. A pergunta que Karam faz é se os tribunais, como o Supremo Tribunal Federal, não deveriam atuar mais como crítico literário do que como autor (do romance da Constituição), e preocupar-se mais com o fundamento de suas interpretações do que com sua originalidade (Karam, 2016; Karam 2017).

8 O capítulo VIII de Dom Quixote, a que me referi como sendo a principal alteração introduzida por Menard, sequer é citado por Borges, que afirma que Menard recriou o IX, XXXVIII e parte do capítulo XXII (Borges, 1998, p. 492).

9 Mimeses, ou narração, é um termo usado por Aristóteles na Poética (1148a a 1449a) para descrever a arte como imitação da natureza, e pode ser traduzida por representação, verossimilhança, ficção, ilusão, referência ou mesmo mentira (Compagnon, 2006, p. 98). 
espelho. Eu, que reflito Borges, que reflete Menard, que reflete Cervantes... E talvez quem lê este artigo seja, ele também, mais um espelho...

É essa trama recursiva que, se bem compreendida, pode nos explicar ${ }^{10}$ muito sobre o autor de uma Constituição. E, sabendo quem é o autor de uma Constituição, talvez possamos compreender se o sentido e a denotação (ou referência) do texto constitucional se assemelham a uma bomba-relógio ou a uma máquina do tempo, ou se eles são apenas como o pêndulo de um relógio.

\section{A CONSTITUIÇÃO COMO ESPELHO}

Essa história de múltiplos espelhos revela o problema ${ }^{11}$ da autoria da Constituição. A Constituição Norte-Americana inicia-se pela fórmula "We, the people": "Nós, o povo". A Filosofia Política não tem nenhuma dificuldade em compreender como um punhado de homens brancos, proprietários de terras e de escravos, podia se conceber como "o povo". Não há nenhuma dificuldade em se explicar como, por um processo de autoengano, uma classe dominante, e agora dirigente, torna opaco o fato de que ela não é o povo, muito mais diverso e heterogêneo do que tal classe. A dificuldade, ao contrário, está em entender como esse conjunto diverso e heterogêneo, formado também pelos escravos e seus descendentes, consegue identificar-se nessa fórmula, "Nós, o povo", ao ler um texto que não foi por ele escrito. Que opacidade é essa que produz um "Nós, o povo" em lugar de "Eles, a elite"? Como o povo, pelo voto, torna-se um com a elite?

Essa não é uma exclusividade da Constituição norte-americana: a Lei Fundamental Alemã diz em seu preâmbulo que ela foi promulgada pelo povo, através de seu poder constituinte, e a Constituição Brasileira afirma em seu preâmbulo, de um modo um pouco mais modesto, que a Constituição foi elaborada, em uma Assembleia Nacional Constituinte, por "nós, representantes do povo brasileiro". Como pode haver representantes, sem que haja representados? Pois, se o povo (norte-americano, alemão, brasileiro) não existia antes da sua Constituição como povo no texto

\footnotetext{
10 Expor de dentro das pregas, das plicas que o escondem no texto, como revela a etimologia da palavra.

11 Sobre o conceito de problema, ver meu artigo, intitulado "A contribuição de Esser para a reconstrução do conceito de princípios jurídicos” (Galuppo, 1999).
} 
constitucional, a quem os representantes representam? Alguém, por exemplo, não votou em nenhum dos deputados constituintes: em que medida os eleitos o representaram? E por que o texto que elaboraram ainda o representa? E por que tal pessoa deve se vincular a um texto que não foi por ele redigido? A questão pode ser ainda mais difícil, se consideramos a situação de alguém que tenha participado do processo eleitoral que constituiu tal assembleia mas cujo candidato não foi eleito. Em que medida tal pessoa pode se sentir representada pelos membros de tal assembleia e vinculada por suas decisões?

Para Jacques Derrida, é preciso prestar atenção não só à fórmula que constitui o preâmbulo dos textos fundacionais, mas também à sua assinatura, se quisermos compreender o que ocorre nesses casos. No caso norte-americano, ao assinarem o texto da Declaração de Independência em nome de um povo que ainda não existia (pois é exatamente esse texto que torna o povo norte-americano distinto do povo do Império Britânico), os signatários constituíram, inventaram o povo que eles diziam representar. Os textos fundacionais não são, portanto, meros atos constatativos, mas também atos performativos, que, cosmogônica e tautologicamente, criam o povo que os cria:

The signature invents the signer [...]. In signing, the people say - and do what they say they do, but in differing and deferring themselves through [...] the intervention of their representatives whose representativity is fully legitimated only by the signature, thus after the fact or the coup [...] - henceforth, I have the right to sign, in truth I will already have had it since I was able to give it to myself (Derrida, 1986, p. 10) ${ }^{12}$.

O constituinte vê em si mesmo um povo que ainda não existe juridicamente como tal e acredita ser um espelho que, magicamente, reflete o povo, através da lógica da representação política. E o efeito produzido por essa mágica consiste em enganar a todos, inclusive a si mesmo: o poder constituinte é o povo! Mas como é possível que ele não reflita apenas a si mesmo?

12 "A assinatura inventa o signatário [...]. Ao assinar, o povo diz - e faz o que eles dizem fazer, mas diferenciando e diferindo a si próprios através [...] da intervenção de seus representantes cuja representatividade é plenamente legitimada apenas pela assinatura, e portanto após o fato ou após o golpe de estado [...] - a partir de então: Eu tenho o direito de assinar, na verdade eu já o teria desde quando eu fui capaz de atribuí-lo a mim mesmo" (minha tradução). 
Aparentemente, a pretensa transparência do autor, que lhe permite se identificar com o destinatário do texto constitucional, é o que produz a opacidade do texto constitucional, sem a qual não poderíamos nos reconhecer como autores da Constituição. Mas essa hipótese esbarra em outra dificuldade: se pensarmos o poder constituinte desse modo, então a Constituição que ele produz também é um engodo, hipótese útil para se pensar certas análises sociológicas do Direito, mas pouco útil para se pensar a dogmática do Direito Constitucional. É preciso propor outra chave de leitura, que já começou a se esboçar acima. A metáfora literária adequada para se pensar a Constituição é o espelho. O espelho que revela escondendo, que esconde revelando. Esconde revelando porque, quando o olhamos, descobrimos quem é o sujeito do texto constitucional, mas isso só pode ocorrer porque não vemos o próprio espelho. Quando, por exemplo, se olha no espelho retrovisor de um carro, só nos tornamos consciente de que ele é um espelho porque não o vemos, e não o vemos porque o que ele revela é algo distinto de si mesmo (a via atrás do carro). Portanto, só nos tornamos consciente do espelho porque não o vemos, e exatamente nisto consiste sua utilidade (um espelho que não refletisse, mas que, ao contrário, permitisse ver a própria superfície do espelho, e não a via atrás, não seria útil como um espelho), e é por isso que ele revela escondendo. O povo está, ao mesmo tempo, oculto e presente na Constituição. O povo, portanto, é alguém como Perseu, que, não podendo olhar a Medusa cara-a-cara, olha-a através de um reflexo no espelho que, na verdade, é sua Égide ${ }^{13}$. Resta sabermos quem é a Medusa.

Diferentemente do mito grego, a Medusa, em nosso caso, é o próprio povo. Mas esse povo não é o povo da Constituição. Michel Rosenfeld nos lembra que "a ordem constitucional requer a imposição de limites à disseminação da identidade comunitária pré-política da nação [...] A identidade constitucional compete com outras identidades relevantes, opondo-se a elas" (Rosenfeld, 2007, p. 21). O povo da Constituição guerreia com o povo empírico. Mas o fato de que a Constituição seja uma negação do povo empírico, o fato de a Constituição dizer que nós somos juridicamente

13 Égide era o escudo que Atena emprestou a Perseu, para que ele cumprisse sua missão de matar uma das Górgonas, a Medusa. Depois da vitória de Perseu, a cabeça da Medusa foi incorporada ao escudo e ele se tornou o Gorgoneion, uma arma mortal, que, quando exibida no campo de batalha, petrifica de medo quem o observa. 
diferentes do que empiricamente $\operatorname{somos}^{14}$, não exclui o fato de que essa identidade empírica é pressuposta dialeticamente pela identidade constitucional:

\begin{abstract}
A identidade constitucional é problemática porque, além de permanecer distinta e oposta a outras identidades relevantes, é inevitavelmente forçada a incorporá-las parcialmente para que [a identidade constitucional] possa adquirir sentido suficientemente determinado (Rosenfeld, 2007, p. 22).
\end{abstract}

Nós somos o povo (Perseu) que vê a Medusa na Égide em que a Constituição se transforma, mas somos também o povo empírico, a própria Medusa, o próprio monstro de que a Constituição nos protege ${ }^{15}$.

No Pierre Menard de Borges, o sentido do texto é o próprio texto, a mise-en-abyme. Mas, como no caso do espelho do carro, quando se vê o espelho, e não o que ele reflete, nada mais se vê. Por isso, se a Constituição é um espelho, ela só pode refletir o que diante dela colocamos: Ela só pode refletir a nós mesmos. Em outros termos, para que a Constituição opere como tal, é preciso interromper o reflexo ao infinito, colocando um observador entre dois espelhos, que passam, então, a refletir os dois lados desse observador. Olhando-se entre dois espelhos, o observador finalmente se torna consciente que possui frente, mas também costas. O povo empírico descobre-se no povo da Constituição. Ao nos vermos no espelho, ocorre o desvanecimento da imagem dos pais fundadores e dos constituintes, produz-se

o desaparecimento necessário daquilo que a funda daquele a quem ela se assemelha e daqueles a cujos olhos ela não passa de semelhança. Esse sujeito - que é o mesmo - foi elidido. E, livre, enfim, dessa relação que a acorrentava, a representação pode se dar como pura representação (Foucault, 1999, p. 21).

O Constituinte apenas cria o espelho, mas não produz o reflexo. Ele se via neste espelho no momento em que o criou, mas não pode ter certeza acerca do que o espelho refletirá no futuro. Ele sequer pode imaginar que o

14 Por exemplo, a Constituição diz que buscamos construir uma sociedade livre, justa, solidária, sem pobreza ou marginalização ou desigualdades sociais (art. $3^{\circ}$ ), e esse princípio permanece válido ainda que seja cotidianamente descumprido nas relações sociais. A Constituição, portanto, refere-se a nós enquanto sujeito constituído pela norma constitucional, e não enquanto sujeito sociológica ou historicamente descrito.

15 Em termos psicanalíticos, nós somos ao mesmo tempo o id reprimido e o super-eu repressor de nós mesmos, a pulsão de amor, mas também de morte, e a civilização repressora dessa pulsão (Freud, 2010). 
objeto que será refletido possua costas. E por isso, quando os textos constitucionais dizem "o povo", não é dos constituintes, ou do que os constituintes pensam ser o povo, que eles falam, pois o reflexo não é produzido apenas pelo espelho, ou apenas pelo objeto mesmo, mas pela interação de ambos. O autor do reflexo é o sujeito que se coloca entre os espelhos, e isso pode ajudar-nos a compreender melhor como interpretamos a Constituição, como conhecemos o espelho.

\title{
MÁQUINA DO TEMPO, BOMBA-RELÓGIO E PÊNDULO: SENTIDO E REFERÊNCIA DA CONSTITUIÇÃO
}

A teoria e a crítica literárias sempre debateram o papel do autor na configuração do texto. Uma das teses mais discutidas da teoria literária do século XX foi a tese da morte do autor, para a qual "o leitor, e não o autor, é o lugar onde a unidade do texto se produz" (Compagnon, 2006, p. 51). O texto se produz no seu destino (o leitor), e não em sua origem (o autor que o escreveu). No entanto, essa tese não implica, de fato, a morte do autor, mas apenas a substituição do conceito tradicional de autor por um outro:

\begin{abstract}
a morte do autor traz, como consequência, a polissemia do texto, a promoção do leitor, e uma liberdade de comentário até então desconhecida; mas, por falta de uma verdadeira reflexão sobre a natureza das relações de intenção e de interpretação, não é do leitor como substituto do autor de que se estaria falando? Há sempre um autor: se não é Cervantes, é Pierre Menard (Compagnon, 2006, p.52).
\end{abstract}

Essa abordagem produziu aquilo que Compagnon chama de interpretação por anacronismo que, considerando o texto como independente da intenção semântica de quem o redigiu, ou seja, como algo que tem existência fora do tempo, o interpreta como algo demiurgicamente ${ }^{16}$ produzido. Contra isso, Rabelais já advertia no prefácio de seu Gargântua e Pantagruel que a culpa por se achar tal intenção semântica no texto original não seria dele, autor, mas do leitor, que o depositou no texto:

\footnotetext{
16 O demiurgo é um deus que, segundo Platão, ao modo de um artesão, cria o mundo sensível $a b$ ovo, a partir da contemplação das ideias, existentes no mundo inteligível (Plato, 1996, p. 448).
} 
Rabelais não critica aqueles que leem um sentido cristão na Ilíada ou nas Metamorfoses, mas somente aqueles que pretendem que Homero e Ovídio haviam posto esse sentido cristão nas suas obras. Em outras palavras, aqueles que lerem em Gargântua um sentido escandaloso, como aqueles que encontrarem um sentido cristão em Homero ou Ovídio, serão [os únicos] responsáveis por isso! (Compagnon, 2006, p. 57).

Essa abordagem anacrônica pensa a interpretação (do texto constitucional) através da metáfora da máquina do tempo: nós, leitores, viajamos até o momento da criação da obra e inserimos ali um sentido (uma bomba) oculto aos olhos do próprio autor, mas que nós mesmos conhecemos e que agora, de volta ao presente, vamos revelar no momento de sua explosão.

Mas é possível, também, o avesso desse discurso. É possível conceber o texto (constitucional) como um cavalo de troia, que traz em seu ventre uma bomba-relógio, um sentido oculto inserido pelo autor primordial (o constituinte) e que somente agora, já no solo do presente, revela-se a nós, invadindo e dominando nossa vida cotidiana.

Nos Estados Unidos, essas duas abordagens correspondem às duas correntes de interpretação constitucional, chamadas de alegorista (ou de Living Constitution) e de originalista. Mas essas duas posições são, ambas, insustentáveis, pois

Se dada geração pode redefinir os primeiros princípios, segundo lhe agrada, significa que não há Constituição. Mas como aceitar, numa democracia moderna, que em nome de uma fidelidade à intenção original, supondo-se que ela seja verificável, os direitos dos vivos sejam garantidos pela autoridade dos mortos? (Compangnon, 2006, p. 59).

Por isso, como obra humana, uma Constituição possui a característica da inesgotabilidade que se faz presente nas grandes obras, que só pode ser entendida se contrapusermos seu sentido (Sinn) a sua referência (Bedeutung $)^{17}$.

17 A tradução mais espontânea do termo Bedeutung seria significado, e o tradutor do livro de Compagnon, em que me baseio em minha análise, prefere utilizar as expressões sentido (para Sinn) e significado (para Bedeutung). No entanto, a tradição analítica da Filosofia da Linguagem tem preferido os termos sentido e referência (ou denotação), respectivamente, pois, como diz Ferrater Mora, "no caso de Frege [adotar a tradução "significado"] se prestaria a confusões. Qualquer das palavras indicadas - denotação, denotatum, referência - é adequada, mas preferimos a última que, além disso, parece ser a que vem circulando mais" (2001, p. 2479). Para uma análise do problema do significado 
Ainda que a distinção entre sentido e referência remonte à lógica de Port Royal, Gottlob Frege foi o responsável por disseminá-la na filosofia da linguagem contemporânea. Enquanto referência (Bedeutung em alemão, ou Reference em inglês, ou ainda denotação, em português) remete àquilo que um nome indica, sentido (Sinn em alemão, e Sense em inglês) remete àquilo que ele expressa, e, portanto, ao modo de se apresentar (ou empregar) o nome. Para ficar com dois exemplos clássicos de Frege, a palavra Odysseus (Frege, 1997, p. 157), como de resto todos os substantivos próprios, possui um sentido (expressa algo), mas não possui uma referência (não permite indicar outro ser a quem possa se aplicar o mesmo nome). Por outro lado, a referência "estrela da manhã" e a referência "estrela da tarde" (Frege, 1997, p. 153) são idênticas (indicam a mesma realidade), mas o sentido não é o mesmo ${ }^{18}$. Sentido e referência são, pois, relativamente independentes.

Enquanto referência remete à denotação, sentido remete à conotação. Por denotação entende-se a extensão semântica de um termo, os elementos que podem ser nomeados por esse termo, e por conotação entende-se as condições de compreensão do termo, ou seja, as condições para que o termo seja aplicado a determinado objeto. O termo "manga", por exemplo, denota objetos assemelhados (por exemplo, Manga Espada, Manga Haden, Manga Palmer), e o termo manga conota objetos distintos (manga como fruta e manga como parte de uma vestimenta). Assim, enquanto referência diz o que um termo abarca em dado momento (o que ele denota), sentido diz a que objetos um termo pode ser aplicado ao alongo do tempo (o que ele conota).

Segundo Compagnon, Hirsch apropriou-se dessa distinção e a converteu em categorias para interpretação do texto na teoria literária:

Hirsch estendeu a distinção ao texto, ao separar seu sentido (meaning) e sua significação (significance) [...] $\mathrm{O}$ sentido, segundo Hirsch, designa aquilo que permanece estável na recepção do texto; ele responde à questão: $\mathrm{O}$

na literatura, ainda que em uma perspectiva ligeiramente distinta da aqui adotada, vejase o seminal artigo de Robert Cover (2016).

18 Um terceiro caso, adaptado a partir de um exemplo de Frege, é, talvez, ainda mais esclarecedor. Imagine a intercessão de três retas (AB, CD e EF). Todas elas se interceptam no mesmo ponto, a que chamaremos de $\mathrm{Z}$. A intercessão da reta $\mathrm{AB}$ e $\mathrm{CD}$ (ponto $\mathrm{Z}$ ) é a mesma da reta $\mathrm{AB}$ e $\mathrm{EF}$ (ponto $\mathrm{Z}$ ), e têm, portanto, a mesma referência (Bedeutung, denotação), mas não possuem o mesmo sentido (Sinn). 
que quer dizer o texto? A significação designa o que muda na recepção de um texto: ela responde à questão: Que valor tem esse texto? O sentido é singular; a significação [referência], que coloca o sentido em relação com a situação, é variável, plural, aberta e, talvez, infinita (Compagnon, 2006, p. 86).

No caso das grandes obras,

cada geração as compreende à sua maneira; isso quer dizer que os leitores nelas encontram algum esclarecimento sobre um aspecto de suas experiências. Mas se uma obra é inesgotável, isso não quer dizer que ela não tenha um sentido original ${ }^{19}$, nem que a intenção do autor não seja o critério deste sentido original. O que é inesgotável é a sua significação ${ }^{20}$, sua pertinência fora do contexto de seu surgimento (Compagnon, 2006, p. 88).

O nível pragmático ${ }^{21}$ do discurso, seu conteúdo ilocucionário ${ }^{22}$, e até perlocucionário, não se identifica, nem se encera, em seu nível semântico, em seu conteúdo locucionário. A distinção entre sentido (que dirige a abordagem originalista) e referência (que dirige a abordagem da Living Constitution), por sua vez, implica que a interpretação do texto constitucional não busca revelar apenas o sentido premeditado pelo autor, mas também a denotação do texto para nós (ainda que o sentido original tenha um papel diretor na busca dessa denotação), pois

19 Sentido, ou seja, Sinn.

20 Referência, ou seja, Bedeutung.

21 A semiologia, que estuda o sistema geral dos signos linguísticos e de sua vida no seio da vida social, entende que a comunicação humana envolve três níveis: o sintático, que analisa a relação dos signos entre si, o semântico, que analisa a relação entre signos e os objetos que eles designam, e o pragmático, que estuda a relação entre signos e os sujeitos envolvidos na comunicação, e portanto o fenômeno da autoridade. Imagine, por exemplo, a seguinte frase: "Cale-se!". Independentemente do falante e do ouvinte, essa frase tem sempre o mesmo conteúdo sintático (é um imperativo que se utiliza de um verbo reflexivo) e semântico (expressa o desejo do falante de que o ouvinte mantenha-se em silêncio). Mas essa mesma frase altera-se do ponto de vista pragmático em função do seu emissor e receptor. Por exemplo: se dita no tribunal por um juiz a um réu, trata-se de uma ordem, e espera-se que produza o efeito perlocucionário de fazer o réu se silenciar, mas se dita pelo réu ao juiz, trata-se de um desacato, e espera-se que produza o efeito perlocucionário de levar o réu a uma pena (Galuppo, 2002, p. 109).

22 Os atos de fala possuem um conteúdo locucionário, um conteúdo ilocucionário e um conteúdo perlocucionário (Galuppo, 2002, p. 111-113). O conteúdo locucionário de um ato de fala é aquilo que é dito, seu significado semântico, sua referência e sua estrutura sintática. O conteúdo ilocucionário pode ser parafraseado como um enunciado performativo (que realiza algo através da comunicação). Por exemplo, "Arrume a cozinha" possui o conteúdo ilocucionário de uma ordem: "Eu ordeno que arrume a cozinha" (Greimas; Courtés, [198?], p. 226). Já o conteúdo perlocucionário não está ligado "nem ao conteúdo próprio do enunciado, nem à sua forma linguística: trata-se de um efeito segundo, como o que produz um discurso eleitoral ao suscitar entusiasmo, convicção ou enfado [...]. Diferentemente da ilocução, em que se produz um efeito dizendo, a perlocução produz um efeito [...] pelo fato de dizer" (Greimas; Courtés, [198?], p. 331). 
numerosas são as implicações e associações de detalhes que não contradizem a intenção principal, mas cuja complexidade é (infinitamente) mais particular, e que não são intencionais no sentido de premeditadas. Entretanto, não é porque o autor não pensou nisso que isso não seja o que ele queria dizer (o que ele tinha, longinquamente, em pensamento). A significação realizada é, apesar disso, intencional em sua inteireza, uma vez que ela acompanha um ato ilocucionário que é intencional. [...] Ter a intenção de fazer alguma coisa devolver a bola para o outro lado da rede, ou compor versos - não exige consciência nem projeto (Compagnon, 2006, p. 91).

O sentido é mais que relevante, pois é condição de intelegibilidade do próprio texto, mas não esgota a referência do texto constitucional, ou de qualquer texto. Pensemos, por exemplo, no recurso retórico-estilístico da ironia: sem invocarmos a intenção do autor (de significar uma coisa, quando na verdade diz e denota outra) ela é completamente incompreensível. Se o sentido não fosse vinculante em nenhuma medida, então a distinção entre criar e interpretar a lei seria impossível. Se houvesse apenas a referência, então todo ato seria um ato de criação do direito ${ }^{23}$.

Portanto, é verdade que não podemos pensar o texto como um texto coerente se não pressupusermos a ação do próprio autor e o sentido que ele atribui ao texto, mas ainda que o sentido original (o que o autor quis dizer em dado momento) exerça um papel diretor na busca de sua significância (o valor que ele possui para nós), o sentido não é exclusivo, nem por ser o único caminho, nem por ser determinante, porque a história do texto é também a história de sua literatura crítica, a história de sua recepção (Compagnon, 2006, p. 80), a história de seu comentário e de sua interpretação, como o caso de Cervantes-Menard-Borges nos revela. Pois, se o sentido fosse o único determinante para a denotação, como poderíamos alterar o próprio texto da Constituição (Rosenfeld, 2007, p. 20), emendando-a, sem trairmos o sentido intentado pelo autor (nós mesmos)

23 Kelsen entende que todo ato de interpretação operado por um órgão do direito é também um ato de criação do direito, porque, na melhor das hipóteses, o intérprete, por exemplo, o juiz, precisa escolher discricionariamente (ou, caso se prefira, irracionalmente) dentre as várias interpretações possíveis aquela que ele aplicará (Kelsen, 1992, p. 240). O argumento de Kelsen é sintaticamente correto, mas não é pragmaticamente correto. Também poderia se dizer que a atividade do poder legislativo não é um ato de criação, mas também de interpretação (e de aplicação) da Constituição (como o próprio Kelsen admite). Mas não dizemos isso, porque a intenção imediata do legislador é de criar o direito (e só mediatamente ele interpreta e aplica o direito), enquanto a intenção imediata do juiz é de interpretar e aplicar o direito (e só mediatamente ele o cria) 
de matar a Medusa? Ainda que, na determinação do sentido do texto do Quixote, a premeditação de Cervantes tenha a primazia, sua denotação (referência) para nós só pode ser revelada quando pensamos em Menard, Borges, no autor do presente artigo e em seu leitor. Nenhum deles, isoladamente, é o autor do texto do ponto de vista dogmático, ainda que possam ser os redatores históricos do texto. É o jogo de espelhos e o sujeito que se interpõe entre eles que é o autor do texto. Da mesma forma, é o jogo de espelhos e o sujeito que se interpõe entre eles que é o autor da Constituição.

É por isso que em seu Pierre Menard, autor do Quixote, Borges afirma que Menard recriou, e não que ele copiou o Quixote:

O texto de Cervantes e o de Menard são verbalmente idênticos, mas o segundo é quase infinitamente mais rico. (Mais ambíguo, dirão seus detratores; mas a ambiguidade é uma riqueza).

Constitui uma revelação cotejar o Dom Quixote de Menard com o de Cervantes. Este, por exemplo, escreveu: ... a verdade, cuja mãe é a história, êmula do tempo, depósito das ações, testemunha do passado, exemplo e aviso do presente, advertência do futuro.

Redigida no século XVII, redigida pelo 'engenho leigo' Cervantes, essa enumeração é mero elogio retórico da história. Menard, em compensação, escreve:

... a verdade, cuja mãe é a história, êmula do tempo, depósito das ações, testemunha do passado, exemplo e aviso do presente, advertência do futuro.

A história, mãe da verdade; a ideia é assombrosa. Menard, contemporâneo de William James, não define a história como indagação da realidade, mas como sua origem. A verdade histórica, para ele, não é o que aconteceu. As cláusulas finais - exemplo e aviso do presente, advertência do futuro - são descaradamente pragmáticas (BORGES, 1998, p. 496).

Agora fica claro que, ao contrário do que poderia pensar o leitor apressado, Borges não está sendo irônico ao dizer que o que parece mera cópia é uma recriação, apesar de o texto ser idêntico, pois, se o sentido é o mesmo, a referência foi mudada, porque o que "mãe da história" denota para um autor espanhol do século XVII não é o mesmo que denota para um argentino do século XX, e muito menos o que pode denotar para um brasileiro no século $\mathrm{XXI}^{24}$.

24 Há um evidente paralelo dessa ideia na obra de Ackerman (1991), We, the People. Segundo o autor, a denotação do texto constitucional norte-americano é profundamente alterada ao longo dos três momenta por que passou a história constitucional norte- 
Nem uma máquina do tempo, nem uma bomba relógio: só podemos interpretar adequadamente a Constituição se considerarmos que o esforço interpretativo é como um pêndulo, que se alterna entre o sentido e a referência do texto, e que calibra a marcha dos ponteiros do relógio, sem fazer com que deixem de ser ponteiros.

\section{REFERÊNCIAS}

ACKERMAN, Bruce. We, the People. Cambridge: Belknap Press, 1991. 3 vols.

ARISTÓTELES. Poética. In: ARISTÓTELES. Os pensadores. Trad. de Eudoro de Souza. São Paulo: Victor Civita, 1973. p. 439 a 533.

BAYARD, Pierre. Como falar dos livros que não lemos? Rio de Janeiro: Objetiva, 2007.

BLOOM, Harold. Don Quijote at 400. The Wall Street Journal, Updated Feb. 23, 2005 12:01 a.m. Disponível em: https://www.wsj.com/articles/SB110912209175261610. Acesso em: 22 out. 2016.

BORGES, Jorge Luís. Pierre Menard, autor do Quixote. In: BORGES, Jorge Luís. Obras completas. Trad. de Carlos Nejar, revisão de Maria Carolina de Araújo. Rio de Janeiro: Globo, 1998. v. I. p. 490-504. [originalmente no livro Ficciones].

CERVANTES SAAVEDRA, Miguel de. O engenhoso fidalgo D. Quixote da Mancha. Trad. de Carlos Nougué e José Luís Sánchez. Rio de Janeiro: Record, 2005.

COMPAGNON, Antoine. O demônio da teoria: literatura e senso comum. Belo Horizonte: UFMG, 2006.

COVER, Robert. Nomos and Narrative $=$ Nomos e narração. Anamorphosis - Revista Internacional de Direito e Literatura, Porto Alegre, RDL, v. 2, n. 2, p. 187-268, jul.-dez. $2016 . \quad$ Doi: http://dx.doi.org/10.21119/anamps.22.187-268.

DERRIDA, Jacques. Declarations of Independence. New Political Science, 7, p. 7-15, Summer 1986.

PRICE, Jorge Eduardo Douglas. «Cambiar el mundo»:¿justicia o utopía? = «Mudar o mundo»: justiça ou utopia?. Anamorphosis - Revista Internacional de Direito e Literatura, Porto Alegre, RDL, v. 3, n. 1, p. 119152, jan.-jun. 2017. Doi: http://dx.doi.org/10.21119/anamps.31.119-152.

americana: o período da fundação até a Guerra Civil, que ele chama de período fundacional, o período da Guerra Civil até o New Deal, que ele chama de República intermediária (Middle Republic) e o período daí em diante, que ele chama de República Moderna. Para maiores detalhes, veja sua obra, em especial o $3^{\circ}$ capítulo (One Constitution, Three Regimes) do $1^{\circ}$ volume (Foundations) e o $2^{\circ}$ capítulo (The Living Constitution) do $3^{\circ}$ volume (Revolution). 
FERRATER MORA, José. Dicionário de filosofia. São Paulo: Loyola, 2001. t. IV (Q-Z). p. 2479 [vocábulo Referência].

FOUCAULT, Michel. As palavras e as coisas. 8. ed. São Paulo: Martins Fontes, 1999.

FREGE, Gottlob. On Sinn and Bedeutung. In: FREGE, Gottlob. The Frege Reader. Malden: Blackwell, 1997. P. 151 a 171. [Michael Beaney (ed.)].

FREUD, Sigmund. O mal-estar na civilização. In: FREUD, Sigmund. $O$ malestar na civilização, Novas conferências introdutórias à psicanálise e Outros textos (1930-1936). Trad. de Paulo César de Souza. São Paulo: Companhia das Letras, 2010. [Obras completas, v. 18].

GALUPPO, Marcelo Campos. A contribuição de Esser para a reconstrução do conceito de princípios jurídicos. Revista de Direito Comparado, Belo Horizonte, v. 3, p. 227-243, maio 1999.

GALUPPO, Marcelo Campos. Igualdade e diferença: Estado Democrático de Direito a partir do pensamento de Habermas. Belo Horizonte: Mandamentos, 2002.

GENETTE, Gérard. Discurso da narrativa. Alpiarca: Vega, 1995.

GREIMAS, A. J.; COURTÉS, J. Dicionário de semiótica. São Paulo: Cultrix, [198?].

KARAM, Henriete. O direito na contramão da literatura: a criação no paradigma contemporâneo, Revista eletrônica do curso de Direito, Santa Maria, v. $12, \quad$ n. $3, \quad$ p. 1022-1043. Doi: http://dx.doi.org/10.5902/1981369429566.

KARAM, Henriete. Nada se cria, tudo se copia. V Colóquio Internacional de Direito e Literatura. Uberaba, 26 a 28 de outubro de 2016. [Conferência]

KELSEN, Hans. Reine Rechtslehre. Wien: Österreichische Staatsdruckerei, 1992.

PLATO. Timaeus. In: PLATO. The Dialogues of Plato. Trad. de Benjamin Jowett. $2^{\text {nd }}$ ed. Chicago: Encyclopaedia Britannica, 1996. [Great Books of the Western World, 6]

ROSENFELD, Michel. A identidade do sujeito constitucional. Belo Horizonte: Mandamentos, 2003.

SHAKESPEARE, William. Hamlet. Trad. de Bárbara Heliodora. Rio de Janeiro: Lacerda, 2004.

Idioma original: Português

Recebido: 12/04/18

Aceito: 28/11/18 